\title{
A ATUAÇÃO DAS FUNDAÇÕES DE APOIO ÀS INSTITUIÇÕES FEDERAIS DE ENSINO SUPERIOR: O ESTUDO DE CASO DA FUNDAÇÃO DE APOIO AO ENSINO, PESQUISA E EXTENSÃO DEPUTADO ÚLTIMO DE CARVALHO, MG - BRASIL
}

\author{
L. F. F. CAMPOS ${ }^{1}$, B. S. OLHER ${ }^{1 *}$ e I. S. COSTA $^{2}$
}

${ }^{1}$ Instituto Federal de Educação, Ciência e Tecnologia do Sudeste de Minas Gerais

${ }^{2}$ Universidade Federal de Viçosa

bruno.olher@ifsudestemg.edu.br*

Artigo submetido em janeiro/2015 e aceito em novembro/2015

DOI: $10.15628 /$ holos.2015.2691

\section{RESUMO}

O Terceiro Setor auxilia o Estado na execução de serviços em que o âmbito público apresenta deficiências e limitações. Dentre estas entidades têm-se as fundações de apoio que visam fornecer suporte administrativo e financeiro às Instituições Federais de Ensino Superior, necessário na execução de seus projetos de pesquisa, ensino e extensão. Esse apoio ser entendido como a captação de recursos bem como o gerenciamento mais ágil e flexível dos mesmos. 0 objetivo do presente trabalho foi analisar a atuação da Fundação de Apoio ao Ensino, Pesquisa e Extensão Deputado Último de Carvalho (FADUC), no tocante à captação e gestão de recursos para o desenvolvimento das atividades do Instituto Federal de Educação, Ciência e Tecnologia do Sudeste de Minas Gerais - Câmpus Rio Pomba. A metodologia utilizada para o desenvolvimento do trabalho foi de natureza descritiva por meio de análise estatística descritiva e análise de conteúdo disponibilizado nos Relatórios de Atividades referentes aos anos de 2011, 2012 e 2013 e documentos internos da FADUC. Os resultados apontaram um crescimento no número de parcerias firmadas pela FADUC, bem como do valor de recursos gerenciados, predominando recursos oriundos do setor público. O número de projetos gerenciados pela mesma manteve-se estável, mas é relevante o crescimento da interação da FADUC com o setor privado. Sendo assim, constatou-se que esta tem apoiado o Câmpus na gestão de seus projetos, mas precisa desenvolver estratégias para melhorar sua atuação na captação de recursos externos destinados ao desenvolvimento de projetos de pesquisa, ensino e extensão.

PALAVRAS-CHAVE: Terceiro setor, Fundações de Apoio, Instituições Federais de Ensino Superior.

\section{THE PERFORMANCE OF SUPPORT FOUNDATIONS TO FEDERAL INSTITUTIONS OF HIGHER EDUCATION: THE CASE STUDY OF EDUCATION SUPPORT FUNDAÇÃO DE APOIO AO ENSINO, PESQUISA E EXTENSÃO DEPUTADO ÚLTIMO DE CARVALHO, MG - BRAZIL}

\begin{abstract}
The Third Sector assists the state in the delivery of services in areas that public sphere has weaknesses and limitations. Among these entities we have the foundations of support that aim to provide administrative and financial support to Federal Institutions of Higher Education, necessary in the execution of their projects of research, teaching and extension. That support can be understood as the fundraising and the most agile and flexible management thereof. The aim of this study was to analyze the performance of the Fundação de Apoio ao Ensino, Pesquisa e Extensão Deputado Último de Carvalho (FADUC), regarding the fundraising and management of resources for the development of activities of the Federal Institute of Education, Science and Technology southeastern Minas
\end{abstract}

Gerais - Campus Rio Pomba. The methodology used for the development of the study was descriptive in nature by means of descriptive statistics and analysis of content available in the Activity Reports for the years 2011, 2012 and 2013 and internal documents of the FADUC. It was observed growth in the number of partnerships by FADUC, and the value of managed resources, prevailing resources from the public sector. The number of projects managed with the public sector remained stable, but is relevant the growth of the interaction of FADUC with the private sector. Thus, it was found that this has supported the Campus in managing their projects, but needs to develop strategies to improve its performance in attracting external resources for development of research projects, teaching and extension.

KEYWORDS: Third sector, Foundations Support, Federal Institutions of Higher Education. 


\section{INTRODUÇÃO}

Até os anos setenta, a ordem sociopolítica era constituída pelo primeiro e o segundo setor, respectivamente, Estado e mercado. Após esse período surgiu o terceiro setor, constituído por organizações privadas com adjetivos públicos e prestadores de serviços de interesse social, sem as limitações do Estado, nem sempre evitáveis e as ambições do mercado, muitas vezes inaceitáveis (ALMEIDA, 2013).

O terceiro setor é composto por associações e entidades não governamentais sem fins lucrativos, buscando complementar as atividades dos setores público e privado, promovendo o bem comum (BLUDENI et al, 2011). Pode-se conceituar terceiro setor como "o conjunto de organismos, organizações ou instituições dotados de autonomia e administração própria que apresentam como função e objetivo principal atuar voluntariamente junto à sociedade civil visando ao seu aperfeiçoamento" (PAES 2010, p. 134). Por meio da participação e atuação em organizações do terceiro setor, a sociedade pode integrar as decisões do governo auxiliando o Estado a suprir as necessidades da coletividade, em especial os serviços sociais, e as necessidades de fortalecimento da sociedade civil organizada.

O terceiro setor, que surge das relações entre o Estado e a sociedade civil organizada, pode firmar parcerias com os setores, público e privado, e destes receber investimentos. Dentro deste contexto, surgem as fundações de apoio às Instituições Federais de Ensino Superior (IFES), visando auxiliar e fomentar os projetos de pesquisa, ensino e extensão desenvolvidos pelas instituições apoiadas. Estas fundações de apoio são de personalidade jurídica de direito privado, criadas por particulares através de escritura pública registrada no Cartório de Pessoas Jurídicas. É importante esclarecer que as fundações de apoio não são criadas por lei e nem mantidas pela União, não se enquadrando na lista de fundações públicas de direito público ou privado (PAES, 2010).

O relacionamento entre as fundações de apoio e as IFES se dá mediante assinatura de convênios, acordos e contratos envolvendo repasse de recurso financeiro. Quando as fundações de apoio realizam o gerenciamento de recursos públicos que Ihe são repassados, elas devem observar os princípios da administração pública, a saber: legalidade, impessoalidade, moralidade, publicidade e eficiência. Assim, as fundações de apoio deverão submeter-se às normas de licitação e contratos da administração pública, especificamente se tratando de contratação de obras, compras e serviços (PAES, 2010).

Além disso, as fundações de apoio estão sujeitas à fiscalização do Ministério Público nos termos do Código Civil e do Código de Processo Civil e à legislação trabalhista (BRASIL, 1994). Em meio às diversas finalidades das fundações de apoio, pode-se destacar o auxílio administrativo e financeiro na execução dos projetos das IFES, por meio da captação de mais recursos, bem como o gerenciamento mais ágil e flexível dos mesmos.

Dentre as instituições que constituem as IFES, têm-se os Institutos Federais de Educação, Ciência e Tecnologia (IF), os quais foram criados no intuito de oferecerem educação profissional e tecnológica nas diferentes modalidades de ensino. Em 2008 foi criado o Instituto Federal de Educação, Ciência e Tecnologia do Sudeste de Minas Gerais (IF Sudeste MG), por meio da fusão de três renomadas instituições federais de ensino, a Escola Agrotécnica Federal de Barbacena, o Colégio Técnico Universitário em Juiz de Fora (CTU-UFJF) e o Centro Federal de Educação Tecnológica de Rio Pomba (CEFET-RP), sendo este último, hoje, o Câmpus Rio Pomba. 
Situada desde 2001 no então CEFET-RP, agora IF Sudeste MG - Câmpus Rio Pomba, a fundação de apoio, na época denominada Fundação de Apoio ao Ensino Tecnológico e Profissionalizante de Rio Pomba (FUNDEPRP). Vale ressaltar que devido a existência de uma outra fundação de apoio possuir a mesma sigla FUNDEP, em janeiro de 2014 a FUNDEP-RP passou a denomina-se Fundação de Apoio ao Ensino, Pesquisa e Extensão Deputado Ultimo de Carvalho (FADUC). Esta fundação de apoio tem apoiado o Câmpus Rio Pomba na gestão dos projetos de pesquisa, ensino e extensão com o objetivo de promover e incentivar o desenvolvimento científico, tecnológico, artístico e cultural. Esta interação, regulamentada pela Resolução no18 de 22 de outubro de 2013, é estratégica para o Câmpus diante da crescente demanda apresentada nos últimos anos para o gerenciamento de recursos oriundos de instituições de fomento, e devido a integração da comunidade acadêmica do Câmpus Rio Pomba com empresas privadas e com a comunidade da cidade de Rio Pomba e região.

Com base na constante alteração da legislação e na dinâmica organizacional própria de uma instituição criada recentemente, sabe-se que são muitos os desafios envolvidos nas atividades da FADUC em apoiar o Câmpus Rio Pomba. Além disso, percebe-se constantemente a insuficiência de recursos destinados ao desenvolvimento de atividades de pesquisa, ensino e extensão, tais como compra de equipamentos e o fomento de projetos nas IFES. Atrelado a este problema, os recursos públicos frequentemente não estão disponíveis no tempo requerido para a realização das atividades dos projetos, ou não podem ser remanejados de acordo com as necessidades de um projeto em andamento.

A atuação das fundações de apoio junto às IFES é ressaltada devido à autonomia administrativo-financeira intrínseca daquelas, visto que possuem maior flexibilidade na realização dos projetos, se ajustando às necessidades e carências das IFES. Desta forma, "o campo do ensino e da pesquisa é um dos mais propícios e férteis à atuação fundacional” (PAES, 2010, p.260). As fundações de apoio assessoram as IFES a transformarem suas ideias em projetos com resultados imediatos e produtivos, ou seja, atuam no desenvolvimento e na transferência do conhecimento entre as IFES e o mercado (ALVES, 2000).

Diante destes fatos, torna-se relevante no campo científico e social a análise da atuação das fundações de apoio, no tocante à captação e gestão de recursos, para o desenvolvimento das atividades da instituição apoiada. Também é fundamental o conhecimento do papel das fundações de apoio, bem como o seu funcionamento de acordo com a legislação vigente.

Desta forma, a presente pesquisa tem por objetivo geral analisar a atuação da FADUC no tocante à captação e gestão de recursos para o desenvolvimento das atividades do IF Sudeste MG - Câmpus Rio Pomba.

\section{REVISÃO BIBLIOGRÁFICA}

A literatura diz que "as fundações de apoio são instituições criadas com a finalidade de dar apoio a projetos de pesquisa, ensino e extensão e de desenvolvimento institucional, científico e tecnológico, de interesse das IFES e também de instituições de pesquisa" (BRASIL 2014).

Estas fundações podem ser criadas por pessoas físicas ou jurídicas. Possuem natureza jurídica de fundações privadas, particulares, sem fins lucrativos, sendo regidas pelo Código Civil e pelo Código Processual Civil Brasileiros. Estão sujeitas ao controle do Ministério Público e do órgão 
superior da instituição de ensino apoiada. Sua criação é mediante aprovação dos seus atos de instituição e do seu respectivo estatuto, pelo Ministério Público onde situa sua sede (PAES, 2010).

As primeiras fundações de apoio surgiram no Brasil na década de 1930 "[...] a fundação de apoio é um instrumento que, se bem regulado pode ser de grande ajuda à realização da missão da universidade em termos de produção e difusão do conhecimento [...]" (ROCHA 2012, p. 02).

Dentre as funções desempenhadas por estas fundações, tem-se a captação de recursos no auxilio as IFES, a busca por mais recursos para as ações de pesquisa, ensino e extensão, além de um melhor gerenciamento desses recursos, tornando o processo de gestão mais ágil e flexível (PAES, 2010). As fundações de apoio podem funcionar como ferramenta de desburocratização da gestão de projetos desenvolvido pelas IFES (ALVES E AZEVEDO 2007).

As relações universidade-empresa, que exigem flexibilidade de gestão e maior liberdade de iniciativa. Segundo ele, "é forçoso reconhecer que as universidades e institutos públicos de pesquisa acham-se submetidos a condições e normas de funcionamento às vezes inadequadas e rígidas para esse propósito" (PAES 2010, p. 263).

Assim, verifica-se a necessidade da atuação das fundações de apoio junto às IFES, pois estas possuem maior flexibilidade na realização de projetos, se ajustando às necessidades e carências das IFES. Desta forma, "o campo do ensino e da pesquisa é um dos mais propícios e férteis à atuação fundacional” (PAES, 2010, p.260).

Em seguida, destaca em seu art. 20, que as fundações de apoio devem ser constituídas como fundações de direito privado, sem fins lucrativos, regidas pelo Código Civil Brasileiro. Estão sujeitas à fiscalização do Ministério Público nos termos do Código Civil e do Código de Processo Civil, à legislação trabalhista e, em especial, ao prévio registro e credenciamento no Ministério da Educação e do Desporto e da Ciência e Tecnologia (BRASIL, 1994).

Por último, conforme os termos do inciso XIII do art. 24 da Lei no 8.666, de 21 de junho de 1993, é permitido às IFES contratar as fundações de apoio, com dispensa de licitação e por prazo determinado, quando estas últimas tiverem como finalidades estatutárias a pesquisa, o ensino ou o desenvolvimento institucional, tiverem inquestionável reputação ético-profissional e forem sem fins lucrativos (BRASIL, 1993; BRASIL, 1994).

A Lei no 8.958, de 20 de dezembro de 1994, também estabelece que as fundações de apoio, ao executarem convênios, contratos, acordos ou ajustes envolvendo recursos públicos, são obrigadas a prestar contas dos recursos aplicados às instituições financiadoras, submeter-se ao controle de gestão pelo órgão máximo da instituição apoiada, bem como submeter-se ao controle finalístico pelo órgão de controle governamental competente (BRASIL, 1994).

É importante observar no art. 40, § 20 da Lei no 8.958/94, que os recursos gerenciados pelas fundações de apoio oriundo de instituições públicas deverão ser mantidos em contas específicas abertas para cada projeto (BRASIL, 1994).

A Figura 1 apresenta aspectos legais das fundações de apoio no Brasil, que visam regulamentar e melhor definir a relação destas com as IFES apoiadas. 


\begin{tabular}{|c|c|}
\hline LEGISLAÇÃO & DESCRIÇÃO \\
\hline $\begin{array}{l}\text { Lei } n^{\circ} 8.958 \text {, de } 20 \text { de dezembro } \\
\text { de } 1994 \text {, alterada pelas Leis } n^{\circ} \\
\begin{array}{c}12.349 \text { de } 15 \text { de dezembro de } \\
2010 \text { e } n^{\circ} 12.863 \text { de } 24 \text { de } \\
\text { setembro de } 2013 .\end{array}\end{array}$ & $\begin{array}{c}\text { Dispõe sobre as relações entre as Instituições Federais de Ensino } \\
\text { Superior e de Pesquisa Científica e Tecnológica e as Fundações de } \\
\text { Apoio e dá outras providências. }\end{array}$ \\
\hline $\begin{array}{c}\text { Decreto } n^{\circ} 7.423 \text {, de } 31 \text { de } \\
\text { dezembro de } 2010 .\end{array}$ & $\begin{array}{l}\text { Regulamenta a Lei } n^{\circ} 8.958 \text {, de } 20 \text { de dezembro de } 1994 \text {, que dispõe } \\
\text { sobre as relações entre as instituições federais de ensino superior e } \\
\text { de pesquisa científica e tecnológica e as fundações de apoio, e revoga } \\
\text { o Decreto } n^{\circ} 5.205 \text {, de } 14 \text { de setembro de } 2004 \text {. }\end{array}$ \\
\hline $\begin{array}{l}\text { Portaria Interministerial } \\
\text { MEC/MCT } \mathrm{n}^{\circ} 3.185 \text {, de } 07 \text { de } \\
\text { outubro de } 2004 \text {, alterada pela } \\
\text { Portaria Interministerial } \\
\text { MEC/MCT no } 475 \text {, de } 14 \text { de abril } \\
\text { de } 2008 \text {. }\end{array}$ & $\begin{array}{l}\text { Dispõe sobre o registro de credenciamento das Fundações de Apoio a } \\
\text { que se refere o inciso III do art. } 2^{\circ} \text {, da Lei } n^{\circ} 8.958 \text {, de } 20 \text { de dezembro } \\
\text { de } 1994 .\end{array}$ \\
\hline $\begin{array}{l}\text { Decreto } n^{\circ} 8.240 \text {, de } 21 \text { de maio } \\
\text { de } 2014 .\end{array}$ & $\begin{array}{l}\text { Regulamenta os convênios e os critérios de habilitação de empresas } \\
\text { referidos no art. } 1^{\circ} \text {-B da Lei } n^{\circ} 8.958 \text {, de } 20 \text { de dezembro de } 1994 \text {. }\end{array}$ \\
\hline $\begin{array}{l}\text { Decreto } n^{\circ} 8.241 \text {, de } 21 \text { de maio } \\
\text { de } 2014 .\end{array}$ & $\begin{array}{c}\text { Regulamenta o art. } 3^{\circ} \text {, da Lei } n^{\circ} 8.958 \text {, de } 20 \text { de dezembro de } 1994 \text {, } \\
\text { para dispor sobre a aquisição de bens e a contratação de obras e } \\
\text { serviços pelas fundações de apoio. }\end{array}$ \\
\hline
\end{tabular}

Figura 1: Principais legislações sobre as fundações de apoio.

Fonte: Elaborado pela autora baseado nas leis, decretos e portarias interministeriais vigentes sobre fundação de apoio.

A transparência na gestão de recursos públicos e privados pelas fundações de apoio é imprescindível, sendo essencial um controle e fiscalização das referidas entidades, pelas instituições financiadoras e pelas instituições apoiadas.

Por meio da elaboração e divulgação de relatórios das atividades desenvolvidas por entidades inseridas no terceiro setor, temos a transparência ou o exercício do controle social (RESENDE, 2006). Gonçalves e Quintana (2011, p. 134) afirmam que "as entidades do terceiro setor podem ter na transparência uma grande credibilidade se suas ações e resultados forem disponibilizados a todos os interessados".

Desta forma, as fundações de apoio anualmente elaboram seus relatórios de atividades, por meio do qual, tornam públicos seus atos de gestão, os projetos gerenciados, eventos realizados ou apoiados, os resultados operacionais obtidos, além de apresentarem o desempenho financeiro alcançado no ano base, ao qual se refere o relatório de atividades.

A Lei $n^{\circ}$ 8.958, de 20 de dezembro de 1994 também discorre sobre a participação de servidores das IFES nas atividades realizadas pelas fundações de apoio. Esta participação deve ser mediante prévia aprovação de norma pelo órgão de direção superior da IFES, dispondo sobre os 
limites e condições previstas em regulamento específico, ajustado entre a IFES e a fundação de apoio.

A participação dos servidores não gera vínculo empregatício de qualquer natureza, podendo as fundações contratadas para sua execução, conceder bolsas de ensino, de pesquisa e de extensão, de acordo com os parâmetros a serem fixados em regulamento. A lei veda a participação do servidor durante a jornada de trabalho a que está sujeito, excetuada a colaboração esporádica, remunerada ou não, em assuntos de sua especialidade (BRASIL, 1994).

A participação de servidores das IFES nos órgãos de direção da fundação de apoio é permitida por lei, sendo esta participação não remunerada, e proibida para servidores investidos em cargos de comissão ou função de confiança (BRASIL, 1994). Em atendimento ao art. 4으, inciso II do Decreto $n^{\circ} 7.423$ de 31 de dezembro de 2010, a composição dos órgãos dirigentes dessas entidades, deve apresentar mais da metade de seus membros indicada pelo órgão colegiado superior da instituição apoiada e, no mínimo, um membro provindo de entidades científicas, empresariais ou profissionais, sem vínculo com a instituição apoiada (BRASIL, 2010).

Ainda de acordo com a Lei $n^{\circ} 8.958 / 94$, as fundações de apoio podem utilizar por meio de instrumento legal próprio, bens e serviços das IFES apoiadas, mediante ressarcimento e pelo prazo necessário à elaboração e desenvolvimento do projeto de ensino, pesquisa e extensão e de desenvolvimento institucional, científico e tecnológico de efetivo interesse das instituições federais contratantes e objeto do contrato firmado entre ambas (BRASIL, 1994).

Visando o auxílio ao desenvolvimento de suas atividades e um maior grau de flexibilidade nas tarefas de pesquisa, ensino e extensão, em 26 de março de 2001, o IF Sudeste MG - Câmpus Rio Pomba, na época Centro Federal de Educação Tecnológica de Rio Pomba (CEFET-RP), criou a fundação de apoio, na época denominada Fundação de Apoio ao Ensino Tecnológico e Profissionalizante de Rio Pomba - FUNDEP-RP, passando esta a ter sua sede localizada em um dos prédios do Câmpus.

Conforme Guimarães "a instituição de ensino superior geralmente é o ente que mobiliza a criação de uma fundação que promoverá, junto daquela, ações de caráter eventual e extraordinário, voltados ao atendimento a demandas educacionais [...]" (GUIMARÃES 2004, p. 13).

A Fundação de Apoio ao Ensino, Pesquisa e Extensão Deputado Último de Carvalho FADUC, tem objetivo de cunho educacional e de desenvolvimento social, econômico, cultural, científico, tecnológico e ambiental, em apoio ao Instituto Federal de Educação, Ciências e Tecnologia do Sudeste de Minas Gerais (FUNDEP-RP, 2011, 2012, 2013).

Conforme FUNDEP-RP, sua missão é facilitar a articulação entre o ensino, a pesquisa e a extensão contribuindo com a educação de qualidade no âmbito do IF Sudeste MG, visando à formação integral e o desenvolvimento sustentável. Ela busca ser referência como facilitadora da melhoria da qualidade na educação profissional e tecnológica, gerindo com eficiência, eficácia e efetividade os projetos de iniciativas dos câmpus parceiros (FUNDEP-RP 2011, 2012, 2013).

Dentre os objetivos da FADUC, descritos em seus Relatórios de Atividades, pode-se destacar o intuito de promover a gestão dos projetos desenvolvidos pela instituição apoiada; promover e incentivar o desenvolvimento de projetos nas áreas da saúde, ciência, do esporte, e da arte e 
cultura; prestar serviços de consultoria e assessoria e/ou atividades econômicas visando obter recurso financeiro para auxiliar nas atividades de pesquisa, ensino e extensão do Câmpus Rio Pomba; oferecer cursos e treinamentos com objetivos científico ou profissionalizante; e celebrar convênios, acordos ou contratos com pessoas físicas ou jurídicas, de direito público ou privado, visando por meio destes, divulgar o conhecimento à comunidade (FUNDEP-RP, 2011, 2012, 2013).

A FADUC possui uma estrutura organizacional definida e organizada, sendo constituída pelo Conselho de Administração com 07 (sete) membros efetivos e seus respectivos suplentes, o Conselho Fiscal com 03 (três) membros efetivos e seus respectivos suplentes, por uma Diretoria Executiva representada por 03 (três) diretores, e 04 (quatro) funcionários (Figura 2).

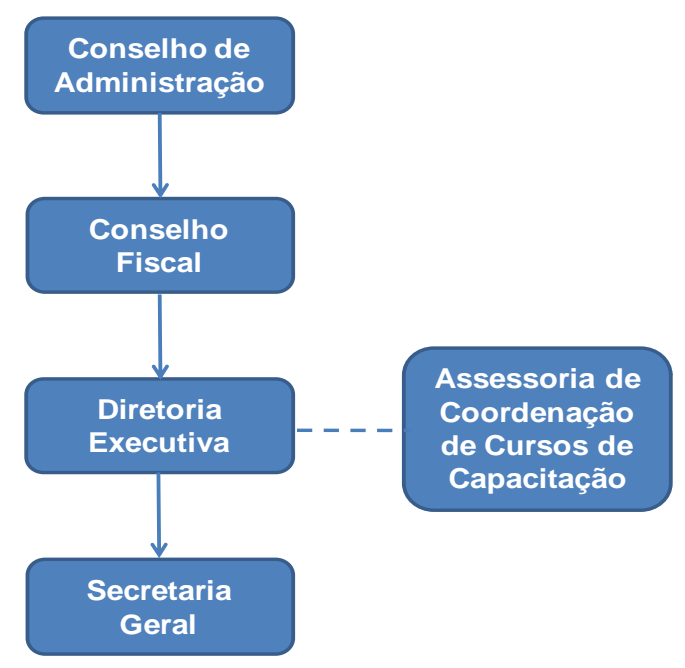

Figura 2: Organograma da fundação de apoio ao ensino, pesquisa e extensão Deputado Ultimo de Carvalho. Fonte: Relatório de atividades da FADUC referente ao ano base de 2013.

Por meio da Resolução nº 18 de 22 de outubro de 2013, o Conselho de Câmpus, órgão superior do IF Sudeste MG - Câmpus Rio Pomba, disciplinou o relacionamento entre este e a Fundação de Apoio ao Ensino Tecnológico e Profissionalizante - FUNDEP-RP, a qual passou a denominar-se Fundação de Apoio ao Ensino, Pesquisa e Extensão Deputado Último de Carvalho FADUC a partir de 01 de janeiro de 2014.

Essa resolução normatiza as ações da fundação de apoio no que tange ao desenvolvimento dos projetos de pesquisa, ensino e extensão relacionados ao IF Sudeste MG - Câmpus Rio Pomba (IFSUDESTEMG - CÂMPUS RIO POMBA, 2013).

Este ato foi de grande relevância devido à crescente demanda apresentada nos últimos anos pelo Câmpus Rio Pomba, por gestão de recursos oriundos de instituições públicas e privadas para a realização de projetos. Esta ação facilita a integração da comunidade acadêmica do Câmpus Rio Pomba com empresas privadas e com a comunidade da cidade de Rio Pomba e região, auxiliando o mesmo no cumprimento de sua missão institucional.

\section{METODOLOGIA}

A presente pesquisa foi realizada na Fundação de Apoio Deputado Ultimo de Carvalho (FADUC), localizada no IF Sudeste de MG - Câmpus Rio Pomba/MG, instituição apoiada por esta fundação. 
Para a classificação desta pesquisa, utilizou-se o critério proposto por Vergara (2010), sendo essa, quanto aos fins classificada como uma pesquisa descritiva, porque expõe características e ações acerca da atuação da fundação de apoio estudada. Quanto aos meios, é classificada como documental e bibliográfica. Documental, pois foi realizada uma investigação nos Relatórios de Atividades dos anos de 2011, 2012 e 2013 da fundação estudada, além de documentos internos da FADUC, tais como, resoluções, estatuto, contratos e convênios assinados nos anos estudados. Uma investigação documental é feita em documentos conservados no interior de órgãos públicos e privados, sendo esta fonte rica, estável e também confiável de dados (VERGARA, 2010). A pesquisa é classificada também bibliográfica, porque foram utilizados materiais bibliográficos sobre o tema trabalhado, tais como, revistas, livros e artigos científicos.

Foram utilizados dados secundários obtidos por meio da análise dos Relatórios de Atividades e documentos internos da FADUC referentes aos anos bases de 2011, 2012 e 2013.

Esta pesquisa utilizou a abordagem quantitativa e a qualitativa. Quantitativa, pois foi realizado a análise dos relatórios de FADUC com o intuito de quantificar em número e percentuais os projetos e recursos gerenciados por tal entidade. Qualitativa, tento em vista que houve a análise das informações descritas nos relatórios de atividades e documentos internos da FADUC.

Para a análise dos dados extraídos das questões fechadas do questionário aplicado junto aos coordenadores de projetos gerenciados pela FADUC nos anos de 2011, 2012 e 2013, utilizouse da estatística descritiva, mais especificamente da distribuição de frequência com auxílio do do software Calc, aplicativo de planilha eletrônica disponível livremente no pacote BR Office.

Para a realização da análise qualitativa, optou-se pela análise de conteúdo que corresponde ao "[...] estudo de textos, documentos e verbalização orais" (VERGARA, 2010, p. 05). Segundo Bardin (1979, p. 44-45), a análise de conteúdo é "um conjunto de técnicas de análise das comunicações [...]" que consiste na sistematização e objetivação do conteúdo das mensagens, buscando indicadores quantitativos ou não. Para a realização da análise de conteúdo, optou-se por elencar as etapas da técnica de acordo com Bardin (1979), sendo elas: a) pré-análise, b) exploração do material e c) tratamento dos resultados, inferência e interpretação dos dados.

\section{RESULTADOS E DISCUSSÔES}

A pesquisa foi realizada a fim de analisar a atuação da Fundação de Apoio ao Ensino, Pesquisa e Extensão Deputado Último de Carvalho (FADUC), no tocante à captação e gestão de recursos para o desenvolvimento das atividades do Instituto Federal de Educação, Ciência e Tecnologia do Sudeste de Minas Gerais - Câmpus Rio Pomba.

Tabela 1: Parcerias da FADUC com o setor público e privado nos anos de 2011, 2012 e 2013.

\begin{tabular}{c|c|c|c|c|c|c}
\hline \multirow{2}{*}{ Setor/Ano } & \multicolumn{2}{|c|}{2011} & \multicolumn{2}{c|}{2012} & \multicolumn{2}{c}{2013} \\
\cline { 2 - 7 } & Quantidade & Percentual \% & Quantidade & Percentual \% & Quantidade & Percentual \% \\
\hline Público & 7 & 78 & 10 & 77 & 7 & 50 \\
\hline Privado & 2 & 22 & 3 & 23 & 7 & 50 \\
\hline Total & $\mathbf{9}$ & 100 & 13 & 100 & 14 & 100 \\
\hline
\end{tabular}

Fonte: Relatórios de atividades da FADUC referente aos anos bases de 2011, 2012 e 2013. 
Analisando os Relatórios de Atividade da FADUC referentes aos anos de 2011, 2012 e 2013, verificou-se que houve um aumento no número de parcerias da fundação de apoio (Tabela 1). Observou-se um predomínio das parcerias com o setor público nos anos de 2011 e 2012, sendo 78\% e 77\% respectivamente. Já em 2013 teve-se uma queda de 30\% em relação a 2012, nas parcerias com o setor público. Concomitantemente observou-se aumento de $250 \%$ no número de parcerias com o setor privado. Em 2013 o número de parcerias com o setor público foi igual ao número de parcerias com o setor privado.

O processo de gerenciamento da FADUC estende-se desde o contato com as financiadoras, ao atendimento do pesquisador e o monitoramento continuado e individualizado dos projetos. Para este trabalho foram considerados os projetos que se iniciaram, os que estão em andamento e aqueles concluídos no período em questão.

Em relação ao número de projetos gerenciado pela FADUC nos anos estudados, observouse que este se manteve praticamente estável, ocorrendo um aumento de 4\% em 2013 em relação aos anos de 2011 e 2012 que se mantiveram iguais (Tabela 2). Dentre os projetos gerenciados, observou-se predominância dos projetos financiados com recursos públicos. Ressalta-se que no exercício de 2013 , verificou-se uma redução de $9 \%$ neste quantitativo.

Esta predominância do financiamento de projetos pelo setor público pode ser atribuída ao fato da FADUC ter um maior número de parceiro oriundos deste setor e pelo crescente incentivo por parte do Estado, no desenvolvimento científico e tecnológico do país. É por meio de órgãos federais e estaduais de fomento à pesquisa, como a FINEP e a FAPEMIG respectivamente, que o Estado investe no desenvolvimento tecnológico e na inovação, fornecendo recursos financeiros para o desenvolvimento de projetos gerenciados pela FADUC.

Além disso, pode-se correlacionar o crescimento no quantitativo de projetos financiados pelo setor privado entre os anos de 2012 e 2013, presente na Tabela 2, com o aumento de parcerias com este setor entre os mesmos anos (Tabela 1).

Tabela 2: Projetos gerenciados pela FADUC com o setor público e privado nos anos de 2011, 2012 e 2013.

\begin{tabular}{c|c|c|c|c|c|c}
\hline \multirow{2}{*}{ Setor/Ano } & \multicolumn{2}{|c|}{2011} & \multicolumn{2}{c|}{2012} & \multicolumn{2}{c}{2013} \\
\cline { 2 - 7 } & Quantidade & Percentual \% & Quantidade & Percentual \% & Quantidade & Percentual \% \\
\hline Público & 20 & 80 & 23 & 92 & 21 & 81 \\
\hline Privado & 5 & 20 & 2 & 8 & 5 & 19 \\
\hline Total & $\mathbf{2 5}$ & $\mathbf{1 0 0}$ & $\mathbf{2 5}$ & $\mathbf{1 0 0}$ & $\mathbf{2 6}$ & 100 \\
\hline
\end{tabular}

Fonte: Relatórios de atividades da FADUC referente aos anos bases de 2011, 2012 e 2013.

A análise das modalidades de projetos gerenciados pela fundação de apoio estudada revelou a predominância de 04 (quatro) modalidades - Cursos, Eventos, Consultoria, e Pesquisa. Em todos os 03 (três) anos analisados, a modalidade de pesquisa foi a predominante, tendo um crescimento de 40\% em 2013, em relação aos 02 (dois) anos anteriores que se mantiveram constante (Tabela 3).

A modalidade Cursos teve uma queda de 50\% entre 2011 e 2013. Este fato pode se atribuído à diminuição da procura de novos cursos de capacitação por parte das prefeituras municipais, sendo estas as principais demandantes desta modalidade de projeto.

Tabela 3: Modalidade de projetos gerenciados pela FADUC nos anos de 2011, 2012 e 2013. 


\begin{tabular}{c|c|c|c|c|c|c}
\hline \multirow{2}{*}{ Modalidade/Ano } & \multicolumn{2}{|c|}{$\mathbf{2 0 1 1}$} & \multicolumn{2}{c|}{$\mathbf{2 0 1 2}$} & \multicolumn{2}{c}{$\mathbf{2 0 1 3}$} \\
\cline { 2 - 7 } & Quantidade & Percentual \% & Quantidade & Percentual \% & Quantidade & Percentual \% \\
\hline Cursos & 10 & 40 & 6 & 24 & 5 & 19 \\
\hline Eventos & 5 & 20 & 8 & 32 & 6 & 23 \\
\hline Consultoria & 0 & 0 & 1 & 4 & 1 & 4 \\
\hline Pesquisa & 10 & 40 & 10 & 40 & 14 & 54 \\
\hline Total & $\mathbf{2 5}$ & $\mathbf{1 0 0}$ & $\mathbf{2 5}$ & $\mathbf{1 0 0}$ & $\mathbf{2 6}$ & $\mathbf{1 0 0}$ \\
\hline
\end{tabular}

Fonte: Relatórios de atividades da FADUC referente aos anos bases de 2011, 2012 e 2013.

Constatou-se também que a modalidade de Consultoria que não se fez ativa no ano de 2011, esteve presente nos anos de 2012 e 2013. O percentual desta modalidade de projetos gerenciados pela FADUC ainda é pequeno em relação às demais modalidades e ao quantitativo de projetos gerenciados por esta fundação de apoio, $4 \%$.

Para o presente trabalho, foram considerados recursos captados, todo aquele recurso totalizante de contratos e convênios assinados pela FADUC com órgãos de fomento federais ou estaduais, prefeituras e empresas públicas ou privadas nos anos em questão. Cabe ressaltar ainda, que a FADUC atua conjuntamente com os pesquisadores do Câmpus Rio Pomba na captação de financiamentos para projetos de pesquisa, ensino e extensão, contribuindo no fortalecimento da instituição apoiada, ampliando a relação institucional nas esferas pública e privada, resultando no desenvolvimento institucional da apoiada, o Câmpus Rio Pomba.

O montante de recursos captados referente às 04 (quatro) modalidades de projetos sob a administração da FADUC apresentou um crescimento de 56\% em 2012 em relação a 2011 e uma queda de 74,5\% em 2013 em relação a 2012 (Tabela 4). Este crescimento no ano de 2012 se deve a 01 (um) único convênio assinado pela FADUC neste ano, que representou 98,4\% do montante de recursos captados na modalidade de pesquisa no ano em questão.

Esta observação aponta para a necessidade da FADUC investir mais na prospecção de projetos de pesquisa, a fim de diversificar as fontes de recursos captados para a modalidade de pesquisa.

Pode-se ainda destacar que a redução no volume de financiamento procedente da modalidade de cursos entre os anos de 2012 e 2013, pode ser relacionada à diminuição da procura de novos cursos de capacitação por parte das prefeituras municipais. Já a queda no montante de financiamento procedente da modalidade de pesquisa é atribuída à redução dos valores totais dos projetos gerenciados pela FADUC, captados por esta e pelos pesquisadores em relação aos anos anteriores estudados.

Tabela 4: Recursos captados pela FADUC por modalidade de projeto nos anos de 2011, 2012 e 2013.

\begin{tabular}{|c|c|c|c|c|c|c|}
\hline \multirow{2}{*}{ Modalidade/Ano } & \multicolumn{2}{|c|}{2011} & \multicolumn{2}{|c|}{2012} & \multicolumn{2}{|c|}{2013} \\
\hline & Reais (R\$) & Percentual \% & Reais (R\$) & Percentual \% & Reais (R\$) & Percentual \% \\
\hline Cursos & $61.706,04$ & 10 & $74.157,98$ & 8 & $23.030,11$ & 9 \\
\hline Eventos & $3.996,10$ & 1 & $10.204,61$ & 1 & $13.900,15$ & 6 \\
\hline Consultorias & 0,00 & 0 & $2.488,00$ & 0 & $1.500,00$ & 1 \\
\hline Pesquisa & $541.860,00$ & 89 & $863.169,37$ & 91 & $203.992,71$ & 84 \\
\hline Total & $607.562,14$ & 100 & $950.019,96$ & 100 & $242.422,97$ & 100 \\
\hline
\end{tabular}

Fonte: Relatórios de atividades da FADUC referente aos anos bases de 2011, 2012 e 2013. 
Para a contabilização de recursos gerenciados, foi considerado o saldo final do ano anterior de cada projeto gerenciado acrescido dos valores creditados ao projeto no decorrer do ano em questão.

Assim, em relação ao montante de recursos gerenciados pela FADUC, observa-se um crescimento de $56 \%$ entre 2011 e 2013. Destes, predominam os recursos oriundos do setor público (Tabela 5). Observa-se ainda, que apesar do aumento no número de parcerias com o setor privado e do aumento no quantitativo de projetos gerenciados pela FADUC financiados por este setor, teve-se uma queda de $57 \%$ no montante de recursos oriundos deste setor entre os anos de 2011 e 2013.

Tabela 5: Recursos gerenciados pela FADUC oriundos do setor público e privado nos anos de 2011, 2012 e 2013.

\begin{tabular}{|c|c|c|c|c|c|c|}
\hline \multirow{2}{*}{ Setor/Ano } & \multicolumn{2}{|c|}{2011} & \multicolumn{2}{|c|}{2012} & \multicolumn{2}{|c|}{2013} \\
\hline & Reais (R\$) & Percentual \% & Reais (R\$) & Percentual \% & Reais (R\$) & Percentual \% \\
\hline Público & $1.035 .068,22$ & 89 & $1.183 .774,99$ & 96 & $\mathrm{R} \$ 1.766 .130,91$ & 97 \\
\hline Privado & $129.848,89$ & 11 & $50.909,42$ & 4 & $\mathrm{R} \$ 55.386,57$ & 3 \\
\hline Total & $1.164 .917,11$ & 100 & $1.234 .684,41$ & 100 & $\mathrm{R} \$ 1.821 .517,48$ & 100 \\
\hline
\end{tabular}

Fonte: Relatórios de atividades da FADUC referente aos anos bases de 2011, 2012 e 2013.

A causa desta queda no montante de recursos oriundos do setor privado deve-se à frequência de projetos de curta duração e de valor monetário mais baixo. Assim, são firmados e gerenciados mais projetos, mas sendo estes de valores menores.

Analisando documentos internos da fundação estudada, pode-se observar que esta mantem os recursos gerenciados oriundos de instituições públicas em contas específicas abertas para cada projeto no início destes e encerradas com a finalização dos projetos. Com isso, verificase que a FADUC está atendendo ao art. $4^{\circ}$, § 2으 da Lei $n^{\circ}$ 8.958/94.

Por fim, pode-se verificar que, houve uma alteração no estatuto da fundação de apoio estudada, visando atendimento ao art. 4을 inciso II do Decreto $n^{\circ} 7.423$ de 31 de dezembro de 2010. Desta forma, a composição dos órgãos dirigentes da FADUC passou a apresentar mais da metade de seus membros indicada pelo órgão colegiado superior da instituição apoiada e, a apresentar um representante da Associação Comercial e Industrial do Município de Rio Pomba/MG, como membro nato, indicado por essa entidade e aprovado pelo Conselho do Câmpus do Instituto Federal de Educação, Ciência e Tecnologia do Sudeste de Minas Gerais - Câmpus de Rio Pomba.

\section{CONCLUSÃO}

Pode-se concluir baseado no presente trabalho, que a FADUC tem atingido seus objetivos, promovendo a gestão dos projetos desenvolvidos pela instituição apoiada, prestando serviços de consultoria e assessoria, oferecendo cursos e treinamentos com objetivos científico ou profissionalizante e celebrando convênios e contratos com pessoas físicas e jurídicas, obtendo recursos financeiros para auxiliar e fomentar as atividades de pesquisa, ensino e extensão do Câmpus Rio Pomba, contribuído assim, para o desenvolvimento institucional do Câmpus. 
Desta forma, esta fundação de apoio tem auxiliado o Câmpus Rio Pomba a transformar suas ideias em projetos com resultados imediatos e produtivos, atuando no desenvolvimento e na transferência do conhecimento como interlocutora entre as IFES e o mercado.

No entanto, destaca-se a necessidade da FADUC traçar e desenvolver ações no intuito de buscar mecanismos de aperfeiçoamento e melhoria contínua de sua atuação frente às atividades de captação de recursos financeiros para o crescente desenvolvimento e fortalecimento das atividades de pesquisa, ensino e extensão do IF Sudeste MG - Câmpus Rio Pomba.

Aponta-se como limitação deste trabalho a não realização da análise da atuação da FADUC no ano de 2014, pois o relatório de atividades deste referido ano não estava aprovado pelos Conselhos da FADUC e nem pelo Conselho de Câmpus quando realizou-se a discussão dos resultados, o que impossibilitou a análise de todos os anos de mandato da última gestão.

A fim de contribuir para pesquisas futuras e colaborar com o desenvolvimento e fortalecimento da FADUC, apresenta-se como sugestão para os próximos trabalhos a realização de um planejamento estratégico para esta fundação de apoio, visando fornecer à sua equipe gestora uma ferramenta que auxilia na tomada de decisão e possibilita atuar de forma pró-ativa com ações concretas e eficazes.

Acredita-se que os resultados desta pesquisa poderão subsidiar futuras ações dos gestores da fundação de apoio e do IF Sudeste MG - Câmpus Rio Pomba, visando melhorar o apoio desta fundação às atividades de pesquisa, ensino e extensão do Câmpus.

\section{REFERÊNCIAS}

1. ALMEIDA, T. A. F. Fundações de Apoio - Regime Jurídico - Autonomia Universitária. Dissertação (Mestrado em Direito). Pontifícia Universidade Católica de São Paulo. São Paulo, SP. 2013.

2. ALVES, A. M. S.; AZEVEDO, M. L. N.. Fundação de Apoio a Universidade: uma discussão sobre o conflito entre o público e o terceiro setor. Atos de Pesquisa em Educação - PPGE/ME FURB. Blumenau, v. 2, n. 3, p. 486-507, set/dez, 2007. Disponível em: <http://proxy.furb.br/ojs/ index.php/atosdepesquisa/article/view/758/634>. Acesso em: 10 de setembro de 2014.

3. ALVES, F. de A. Fundações, organizações sociais, agências executivas: organizações da sociedade civil de interesse público e demais modalidades de prestação de serviço público. São Paulo: LTR, 2000. 344p.

4. BARDIN, L. Análise de Conteúdo. Tradução Luiz Antero Reto, Augusto Pinheiro Lisboa: Edições 70, 1979. 280p.

5. BLUDENI, L. M. et al. Aspectos Gerais do Terceiro Setor, In: Comissão de Direito do Terceiro Setor da OAB São Paulo, 2011, São Paulo. Cartilha. São Paulo: OAB São Paulo , 2011. Disponível em: <http://www.oabsp.org.br/comissoes2010/direito-terceirosetor/cartilhas/REVISaO\%202 011Cartilha_Revisao_2007_Final_Sem\%20desta que\%20de\%20alteracoes.pdf>. Acesso em: 04 de setembro de 2014.

6. BRASIL. Lei $\mathbf{n}^{\circ} \mathbf{8 . 6 6 6}$ de $\mathbf{2 1}$ de junho de 1993. Regulamenta o art. 37, inciso XXI, da Constituição Federal, institui normas para licitações e contratos da Administração Pública e dá outras 
providências. Brasília, DF. Disponível em: <http://www.planalto.gov.br/ccivil_03/leis/l8666 cons.htm>. Acesso em: 05 de setembro de 2014.

7.

Lei $\mathrm{n}^{\circ} \mathbf{8 . 9 5 8}$ de 20 de dezembro de 1994. Dispõe sobre as relações entre as instituições federais de ensino superior e de pesquisa científica e tecnológica e as fundações de apoio e dá outras providências. Brasília, DF. Disponível em: <http://www.planalto.gov.br/ ccivil_03/leis//8958.htm>. Acesso em: 04 de setembro de 2014.

8. Lei $\mathbf{n}^{\circ} \mathbf{1 0 . 4 0 6}$, de 10 de janeiro de 2002. Institui o Código Civil. Brasília, DF. Disponível em: < http://www.planalto.gov.br/ccivil_03/leis/2002/I10406.htm>. Acesso em: 18 de setembro de 2014.

9. Ministério da Educação e o Ministério da Ciência e Tecnologia. Portaria Interministerial $n^{\circ} \mathbf{3 . 1 8 5}$ de 14 de setembro de 2004. DOU de 8 de outubro de 2004, Seção 1 , p. 17. Disponível em: <http://portal.mec.gov.br/dmdocuments/portaria_3185_atual_sesu. $p d f>$. Acesso em: 18 de setembro de 2014.

10. Ministério da Educação e o Ministério da Ciência e Tecnologia. Altera a Portaria Interministerial MEC/MCT $n^{\circ} 3.185$, de 07 de outubro de 2004. Portaria Interministerial $\mathbf{n}^{\circ}$ 475 de 14 de abril de 2008. DOU de 30 de maio de 2008, Seção 1, p. 13. Disponível em: <http://www.fco.eng.ufmg.br/fco/jsp/geral/legislacao/Portaria\%20Interministerial\%20475_ 2008.pdf>. Acesso em: 18 de setembro de 2014.

11.

Decreto $n^{\circ} \mathbf{7 . 4 2 3}$, de 31 de dezembro de 2010. Regulamenta a Lei no 8.958, de 20 de dezembro de 1994, que dispõe sobre as relações entre as instituições federais de ensino superior e de pesquisa científica e tecnológica e as fundações de apoio, e revoga o Decreto no 5.205, de 14 de setembro de 2004. Brasília, DF. Disponível em: < http://www.planalto. gov.br/ccivil_03/_Ato2007-2010/2010/Decreto/D7423.htm >. Acesso em: 04 de setembro de 2014.

12. Lei $\mathbf{n}^{\circ} \mathbf{1 2 . 3 4 9}$ de $\mathbf{1 5}$ de dezembro de $\mathbf{2 0 1 0}$. Altera as Leis $\mathrm{n}^{\circ \mathrm{s}} \mathbf{8 . 6 6 6}$, de 21 de junho de 1993, 8.958, de 20 de dezembro de 1994, e 10.973, de 2 de dezembro de 2004; e revoga o $\S$ 1ㅇ do art. 20 da Lei $\mathrm{n}^{\circ} 11.273$, de 6 de fevereiro de 2006. Brasília, DF. Disponível em: < http://www.planalto.gov.br/ccivil_03/_Ato2007-2010/2010/Lei/L12349.htm>. Acesso em: 18 de setembro de 2014.

13. Lei $\mathbf{n}^{\circ} \mathbf{1 2 . 8 6 3}$ de 24 de setembro de $\mathbf{2 0 1 3}$. Altera a Lei $\mathrm{n}^{\circ} 12.772$, de 28 de dezembro de 2012, que dispõe sobre a estruturação do Plano de Carreiras e Cargos de Magistério Federal; altera as Leis nos 11.526, de 4 de outubro de 2007, 8.958, de 20 de dezembro de $1994,11.892$, de 29 de dezembro de 2008, 12.513, de 26 de outubro de 2011, 9.532, de 10 de dezembro de 1997, 91, de 28 de agosto de 1935, e 12.101, de 27 de novembro de 2009; revoga dispositivo da Lei no 12.550, de 15 de dezembro de 2011; e dá outras providências. Brasília, DF. Disponível em: <http://www.planalto.gov.br/ccivil_03/_ato2011-2014/2013/Lei/L12863. htm>. Acesso em: 18 de setembro de 2014.

14.

Decreto $n^{\circ} \mathbf{8 . 2 4 0}$, de 21 de maio de 2014. Regulamenta os convênios e os critérios de habilitação de empresas referidos no art. 10-B da Lei n 8.958, de 20 de dezembro de 1994. Brasília, DF. Disponível em: <http://www.planalto.gov.br/ccivil_03/_Ato2011-2014/2014/De creto/D8240.htm>. Acesso em: 04 de setembro de 2014.

15.

Decreto $n^{\circ}$ 8.241, de 21 de maio de 2014. Regulamenta o art. 3이 da Lei $n^{\circ} 8.958$, de 20 de dezembro de 1994, para dispor sobre a aquisição de bens e a contratação de obras e serviços pelas fundações de apoio. Brasília, DF. Disponível em: <http://presrepublica.jusbrasil. 
com.br/legislacao/120002504/decreto-8241-14>. Acesso em: 04 de setembro de 2014.

16. FUNDAÇÃO DE APOIO AO ENSINO TECNOLÓGICO E PROFISSIONALIZANTE DE RIO POMBA. Relatório de Atividades de 2011. Rio Pomba, MG, 2012.

17. ___ Relatório de Atividades de 2012. Rio Pomba, MG, 2013.

18. _. Relatório de Atividades de 2013. Rio Pomba, MG, 2014.

19. GONÇALVES, T. L.; QUINTANA, A. C. A Importância da Transparência na Gestão de Recursos Públicos, em Fundações de Apoio a Pesquisa e Extensão. Revista Gestão Universitária na América Latína, Florianópolis, v. 4, n. 2, p. 123-145, mai/ago, 2011. Disponível em: <https://periodicos.ufsc.br/index.php/gual/article/view/19834535.2011v4n2p123/22002>. Acesso em: 04 de setembro de 2014.

20. GUIMARÃES, N. A. Fundações Privadas de Apoio às Instituições de Ensino Superior: Breves Considerações. 2004. Disponível em: <http://empreende.org.br/pdf/ONG's,\%200SCIP'S\%20 e\%20Terceiro\%20Setor/Funda\%C3\%A7\%C3\%B5es\%20privadas\%20de\%20apoio\%20\%C3\%A0 s\%20institui\%C3\%A7\%C3\%B5es\%20de\%20ensino\%20superi.pdf >. Acesso em: 25 de setembro de 2014.

21. IFSUDESTEMG - CÂMPUS RIO POMBA. Resolução $\mathbf{n}^{\circ}$ 18, de 22 de outubro de 2013. Disciplina o relacionamento entre o Instituto Federal de Educação, Ciências e Tecnologia do Sudeste de Minas Gerais - Câmpus Rio Pomba e a Fundação de Apoio ao Ensino Tecnológico e Profissionalizante. Rio Pomba, MG, 22 de outubro de 2013.

22. MINISTÉRIO DA EDUCAÇÃO. Fundações de Apoio - Apresentação. Disponível em: <http://portal.mec.gov.br/index.php?ltemid=1022\&>. Acesso em 04 de setembro de 2014.

23. OLIVEIRA, E. et al. Análise de conteúdo e pesquisa na área da educação. Revista diálogo educacional, v. 4, n. 9, p. 1-17, 2003. Disponível em: http://www.redalyc.org/articulo.oa?id $=189118067002$. Acesso em: 10 de outubro de 2014 .

24. PAES, J. E. S. Fundações, associações e entidades de interesse social: aspectos jurídicos, administrativos, contábeis, trabalhistas e tributários. 7. ${ }^{\text {a }}$ ed. - São Paulo: Forense, p. 259-295. 2010.

25. RESENDE, T. A. Roteiro do Terceiro Setor. Associações e Fundações: o que são, como instituir, administrar e prestar contas. 3 ed. Belo Horizonte: Prax, 2006.

26. ROCHA, José Claudio. O papel das fundações de apoio no contexto das universidades públicas no Brasil. In: Âmbito Jurídico, Rio Grande, XV, n. 100, maio 2012. Disponível em: <http://www.ambito-juridico.com.br/site/?n_link=revista_artigos_leitura\&artigo_id=11646> . Acesso em: 20 de agosto de 2014.

27. SEBRAE MG. Manual de Políticas Públicas: Conceitos e Práticas. Série Políticas Públicas, v. 7, 2008, 48p. Disponível em: <http://www.agenda21comperj.com.br/sites/localhost/files/MA NUAL\%20DE\%20POLITICAS\%20P\%C3\%9ABLICAS.pdf>. Acesso em: 20 de agosto de 2014.

28. VERgARA, S. C.. Projetos e Relatórios de Pesquisa em Administração. 12ạ ed. São Paulo: Atlas, 2010. 94p. 